\title{
Synthesis of Large Crystal Transition Metal Substituted Zeolite ZSM-5
}

\author{
Tara L. Schaeffer ${ }^{1}$ and Scott J. Kirkby*,2 \\ ${ }^{1}$ Department of Chemistry, University of Missouri-Rolla, 142 Schrenk Hall, Rolla, Mo 65409, USA \\ ${ }^{2}$ Department of Chemistry, East Tennessee State University, Box 70695, Johnson City, TN 37614, USA
}

\begin{abstract}
Crystals of ZSM-5 containing $\mathrm{Cu}, \mathrm{Mn}$, and Fe have been synthesized up to $85 \mu \mathrm{m}$ in length along the long axis. This is 1 to 2 orders of magnitude larger than any previously reported. Phase identification was accomplished by powder XRD. A modified Charnel's method was used to chelate the transition metal and the aluminum in the synthesis gel. Elemental analysis was performed by ICP-AES, confirming the presence of the metals. The metals are resistant to leaching under ion exchange and, as determined by partial dissolution, incorporated throughout the volume of the crystals.
\end{abstract}

Keywords: Zeolite, ZSM-5, large crystal, transition metal, Charnell's method.

\section{INTRODUCTION}

Metal substituted ZSM-5 has been shown to have many potential uses as catalysts [1-4]. Despite significant effort [57] very little is known about how the metals are incorporated into the framework. For example, it is not yet certain why the metal sites do not all have equal catalytic activity [8,9]. Thus, more needs to be known about the local environment of the catalytically active metal sites. This may be partially accomplished by NMR diffusion studies. Using randomly oriented polycrystalline samples greatly increases the complexity of the data analysis. However, if sufficiently large crystals can be synthesized they may be aligned in a single orientation in a matrix of capillary tubes [10]. If the knowledge of the diffusion pattern through the transition metal substituted ZSM-5 could be improved, a better understanding of the different catalytic activity of the metal might result.

Unsubstituted large crystals of ZSM-5 have been synthesized by several groups. Mueller reports crystals of up to 350 $\mu \mathrm{m}$ using colloidal silica and ammonia [11]. Crystals of up to $200 \mu \mathrm{m}$ were synthesized using colloidal silica and sodium hydroxide [12]. A modified Charnell's method, which uses a surfactant to chelate the aluminum, was used to synthesize crystals of up to $220 \mu \mathrm{m}$. Triethylenetetramine was used as both the chelating agent and the template molecule [13]. Lermer reported synthesizing crystals of up to $280 \mu \mathrm{m}$ [14]. Hayhurst conducted a study to determine what factors affect the crystal size of ZSM-5. Several different factors were considered, including, the content of silica, tetrapropyl ammonium (TPA), water, aluminum and sodium. It was found that a reduction in aluminum in the gel appeared to lead to larger crystals, supporting the theory that aluminum leads to increased nucleation, which in turn leads to decreased crystal size $[13,15]$. It was also discerned that the more dilute systems encourage larger crystals, but extremely dilute systems can have the opposite effect. The influence

*Address correspondence to this author at the Department of Chemistry, East Tennessee State University, Box 70695, Johnson City, Tennessee 37614, USA; Fax: 1-423-439-5835; Tel: 1-423-439-5823;

E-mail: kirkby@etsu.edu that the other parameters have on crystal size is not clear. The largest crystals obtained from this study were $300 \mu \mathrm{m}$ [15].

Many metal containing zeolites have been made by ion exchange. This, however, has some disadvantages. When metals are introduced by ion exchange, this allows the possibility of the metal ions being leached during the catalysis process. With the metal being incorporated into the framework, the metal should be more secure. The incorporation of metals into the framework has been shown to be successful in other zeolites [16].

\section{EXPERIMENTAL}

The transition metal containing zeolites were synthesized by adding salts of the desired metals directly to the synthesis gel. Two transition metal free syntheses were used as reference preparations. The first was based on a preparation by Mueller [11]. To increase the crystal size the synthesis gel was diluted by $14 \%$ resulting in the gel composition below:

$$
8 \text { TPA:123 }\left(\mathrm{NH}_{4}\right)_{2} \mathrm{O}: \mathrm{Al}_{2} \mathrm{O}_{3}: 59 \mathrm{SiO}_{2}: 2600 \mathrm{H}_{2} \mathrm{O}
$$

The gel was placed in $45 \mathrm{ml}$ PTFE lined stainless steel acid digestion vessels (Parr) and heated statically at $180^{\circ} \mathrm{C}$ for seven days. This yielded many regular, well shaped crystals of $25 \mu \mathrm{m}$. It was found that increasing the water content to 3000 resulted in crystals of $10-12 \mu \mathrm{m}$.

The second reference preparation used, had a high silicon content $(\mathrm{Si} / \mathrm{Al}=600)$ [17]. Its molar composition was:

$$
\text { TPAOH:0.0162 } \mathrm{Al}_{2} \mathrm{O}_{3}: 19.46 \mathrm{SiO}_{2}: 438 \mathrm{H}_{2} \mathrm{O}
$$

As before the gel was placed in a $45 \mathrm{ml}$ PTFE lined acid digestion vessel and heated, without agitation, at $180^{\circ} \mathrm{C}$ for three days. This preparation resulted in crystals of up to 80 $\mu \mathrm{m}$. Adjusting the $\mathrm{Si} / \mathrm{Al}$ ratio to 800 , produces a gel with the molar composition of:

$$
\text { TPAOH:0.0162 } \mathrm{Al}_{2} \mathrm{O}_{3}: 25.92 \mathrm{SiO}_{2}: 438 \mathrm{H}_{2} \mathrm{O}
$$

Which resulted in crystals of up to $50-60 \mu \mathrm{m}$ using the procedure as above. The surfactant triethylenetetramine 
(trien) was added to both of the preparations in an effort to increase crystal size. This resulted in gel compositions of:

\section{TPAOH:0.0162 $\mathrm{Al}_{2} \mathrm{O}_{3}: 19.46 \mathrm{SiO}_{2}: 438 \mathrm{H}_{2} \mathrm{O}: 2$ trien and}

$$
\text { TPAOH:0.0162 } \mathrm{Al}_{2} \mathrm{O}_{3}: 25.92 \mathrm{SiO}_{2}: 438 \mathrm{H}_{2} \mathrm{O}: 2 \text { trien }
$$

In the first case, this resulted in crystals of 50-60 $\mu \mathrm{m}$ with a marked decrease in the amount of amorphous and microcrystalline material that accompanied the crystals. In the second case, there was not a decrease in the undesired material. The crystals were up to $56 \mu \mathrm{m}$.

The metals were introduced directly into the reference synthesis gels. Copper was introduced as copper nitrate, manganese as manganese acetate, iron (II) as iron oxalate and iron (III) as iron nitrate. The synthesis procedures were otherwise the same as the unsubstituted preparations. The gel compositions used were:

TPAOH:0.0162 $\mathrm{Al}_{2} \mathrm{O}_{3}: 25.92 \mathrm{SiO}_{2}: 438 \mathrm{H}_{2} \mathrm{O}: 0.2596 \mathrm{M}$, where $\mathrm{M}=\mathrm{Cu}, \mathrm{Mn}$, or $\mathrm{Fe}$

\section{TPAOH:0.0162 $\mathrm{Al}_{2} \mathrm{O}_{3}: 19.46 \mathrm{SiO}_{2}: 438 \mathrm{H}_{2} \mathrm{O}: 0.0194 \mathrm{M}: 2$ trien, where $\mathrm{M}=\mathrm{Cu}, \mathrm{Mn}$ or $\mathrm{Fe}$}

The resulting products were examined under an optical microscope for morphology and size. The products were

a

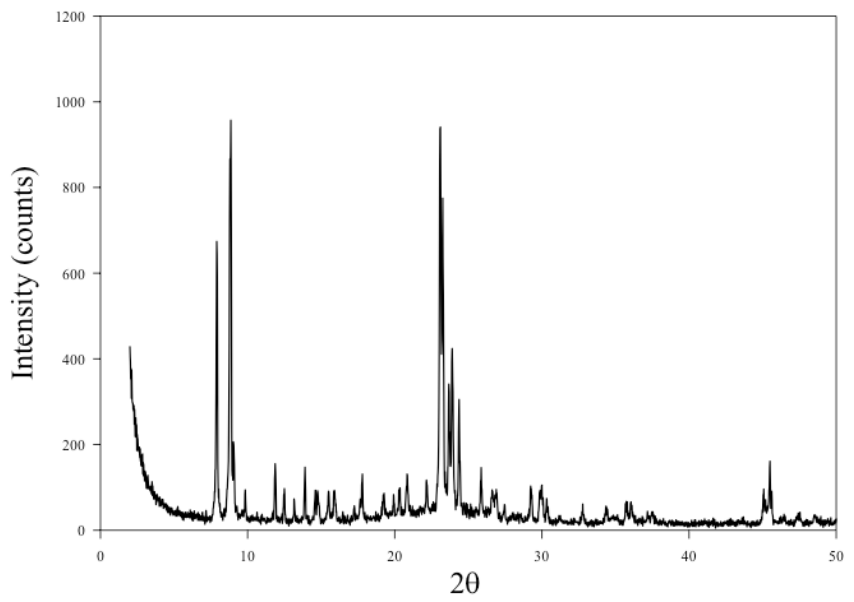

$\mathrm{c}$

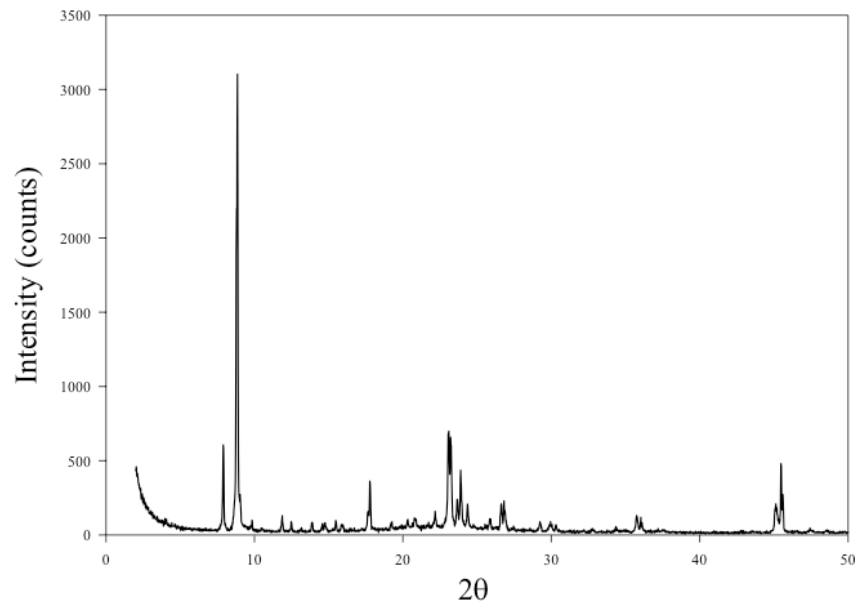

analyzed by XRD to confirm the identity of the phase. Scanning electron microscopy was used to observe the morphology in detail for the more successful preparations. Inductively coupled plasma-atomic emission spectroscopy (ICPAES) [18] was used to confirm the presence of metal in the product.

Portions of the batches were also washed with a $1.0 \mathrm{M}$ solution of $\mathrm{HCl}$ in methanol for one hour to remove the surface of the crystals and any stray amorphous material. These samples were also analyzed by ICP-AES.

The powder X-ray diffraction (XRD) was performed using a Scintag PAD-V with a liquid nitrogen cooled $\mathrm{Ge}$ detector. A Hitachi S-4700 field emission scanning electron microscope was used for the microscopy.

\section{RESULTS AND DISCUSSION}

Phase pure, highly crystalline materials were prepared by the direct incorporation of the transition metal into the gel for $\mathrm{Cu}, \mathrm{Mn}$ and $\mathrm{Fe}$ (see Fig. 1). It was found that substituting the metals for $\sim 0.1 \%$ of the $\mathrm{T}$ atoms was the upper limit for the formation of discrete large crystals. The amount of metal in the gel with respect to the T-atoms was compared to the amount of metal in the product (\%T-atoms, see Table 1). It may be seen that for all cases except the sample containing

b
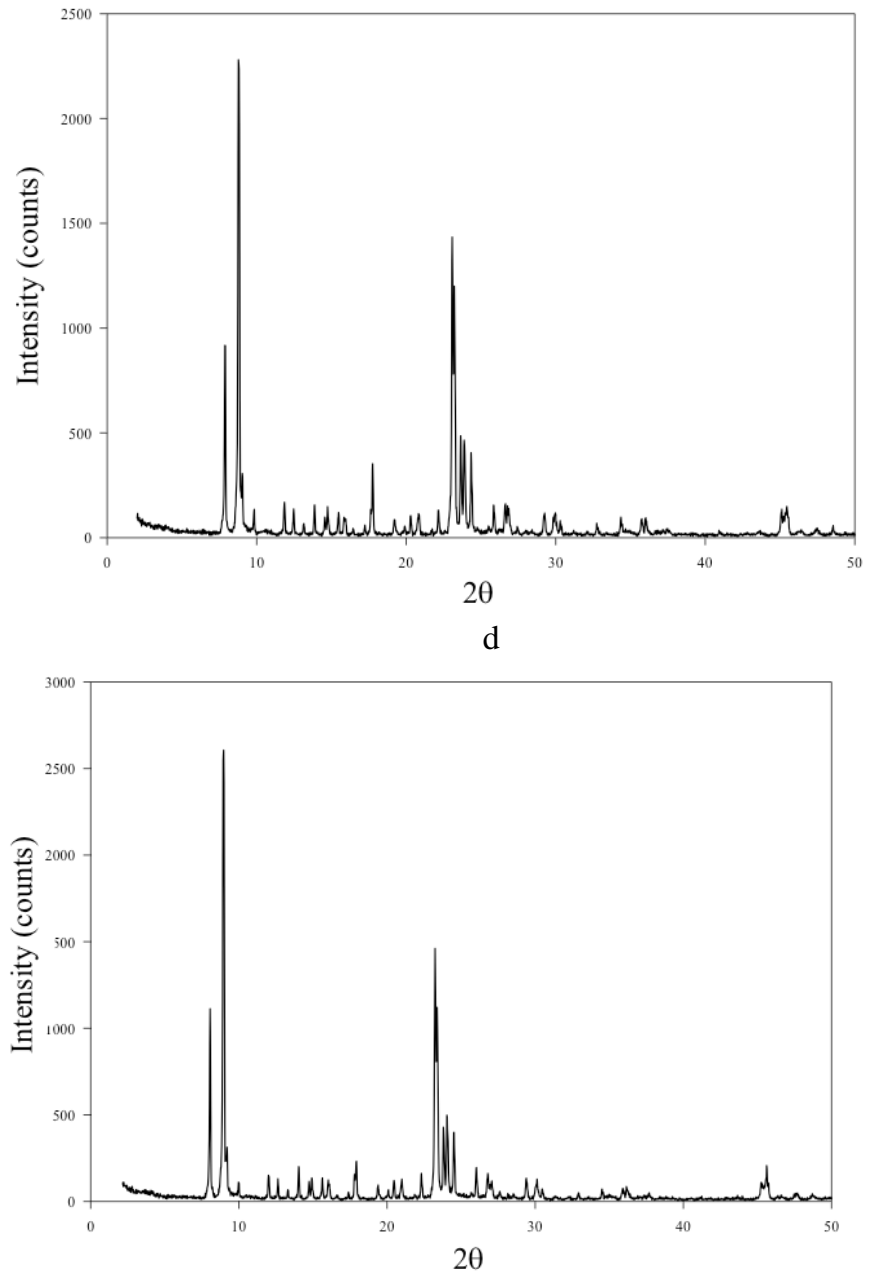

Fig. (1). Powder X-ray diffraction patterns for (a) $\mathrm{Cu}^{2+}$, (b) $\mathrm{Mn}^{2+}$, (c) $\mathrm{Fe}^{2+}$, and (d) $\mathrm{Fe}^{3+}$ substituted ZSM-5. 
Table 1. Maximum Crystal Size and Transition Metal Content for the Transition Metal Substituted ZSM-5

\begin{tabular}{|c|c|c|c|}
\hline Ion & Maximum Size $(\boldsymbol{\mu m})$ & Amount of Metal in Gel (\% of T-atoms) & Amount of Metal in Product (\% of T-atoms) \\
\hline \hline $\mathrm{Cu}^{2+}$ & 40 & 0.1 & 0.607 \\
\hline $\mathrm{Mn}^{2+}$ & 50 & 0.1 & 0.211 \\
\hline $\mathrm{Fe}^{2+}$ & 87 & 0.1 & 0.979 \\
\hline $\mathrm{Fe}^{3+}$ & 62 & 0.1 & 0.081 \\
\hline
\end{tabular}

$\mathrm{Fe}^{3+}$ the product contains a higher percentage of metal atoms in the product than in the gel. The $\mathrm{Fe}^{3+}$ sample was prepared with the surfactant, triethylenetetramine. It is probable that a majority of the iron was chelated and was not incorporated into the framework.

Scanning electron microscopy was used to observe the crystal morphology (see Fig. 2). Crystal twinning, a common growth artifact with ZSM-5, can easily be seen in the SEM image of a crystal synthesized with $\mathrm{Fe}^{2+}$.

Crystals using the dilute version of Mueller's gel were synthesized containing $\mathrm{Cu}, \mathrm{Mn}$, and Fe. Just as for the transi-

\section{a}

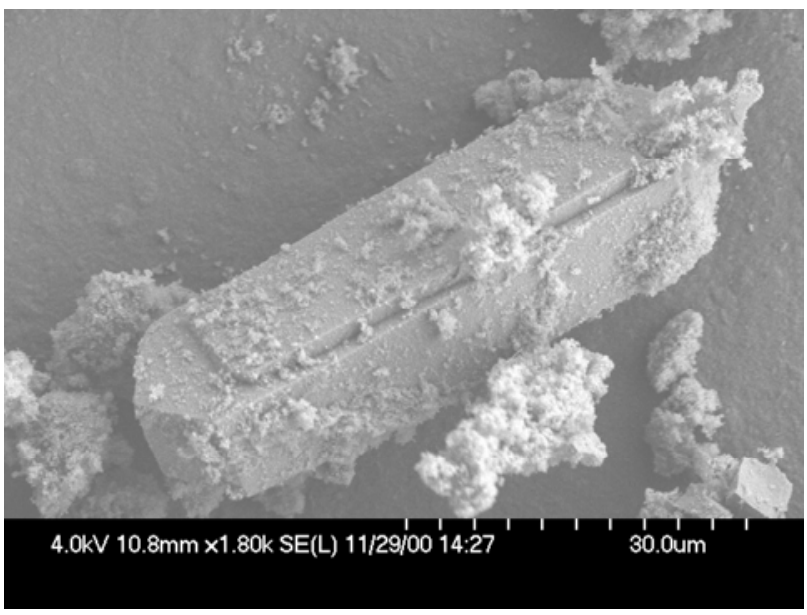

$\mathrm{c}$

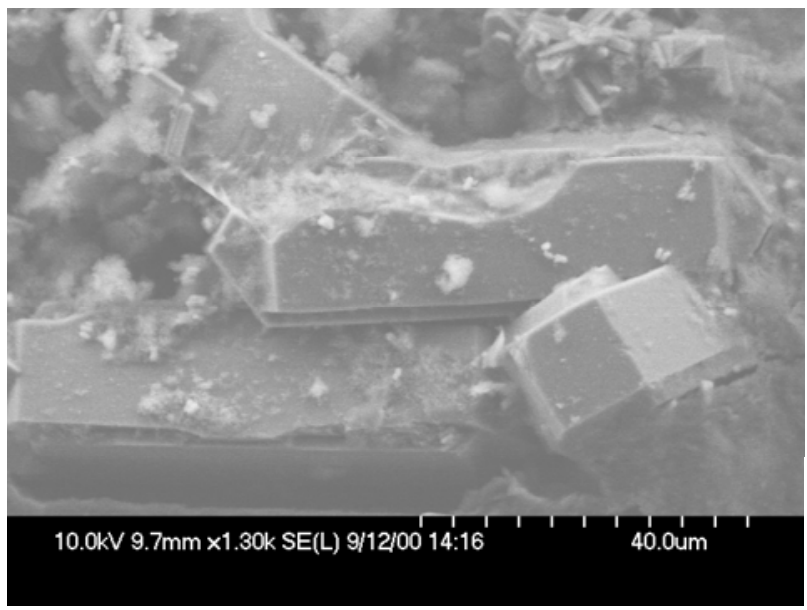

tion metal free preparation, all were well shaped and did not show the twinning observed in the larger crystals. These were up to $10 \mu \mathrm{m}$ in size (see Fig. 3).

The transition metal analysis for the acid washed samples is given in Table 2. The relative amount of transition metal present in the crystal decreased after the acid washing. It did not however, vanish. Thus while the transition metal content is richer in the outer portions of the crystals, metals where incorporated throughout the crystal volume. This would clearly indicate that the transition metal content is not in only on the external surface or in the extraneous material. It is probable that more of the aluminum sites are available for

b

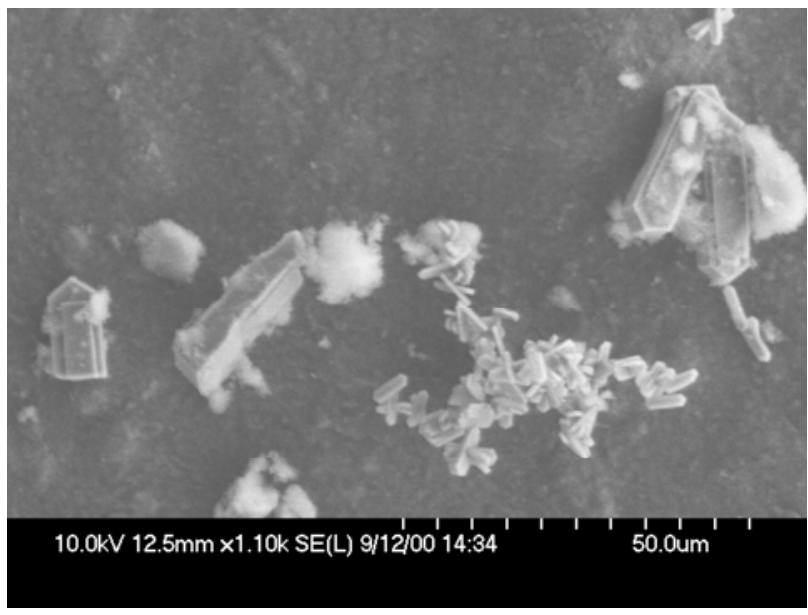

d

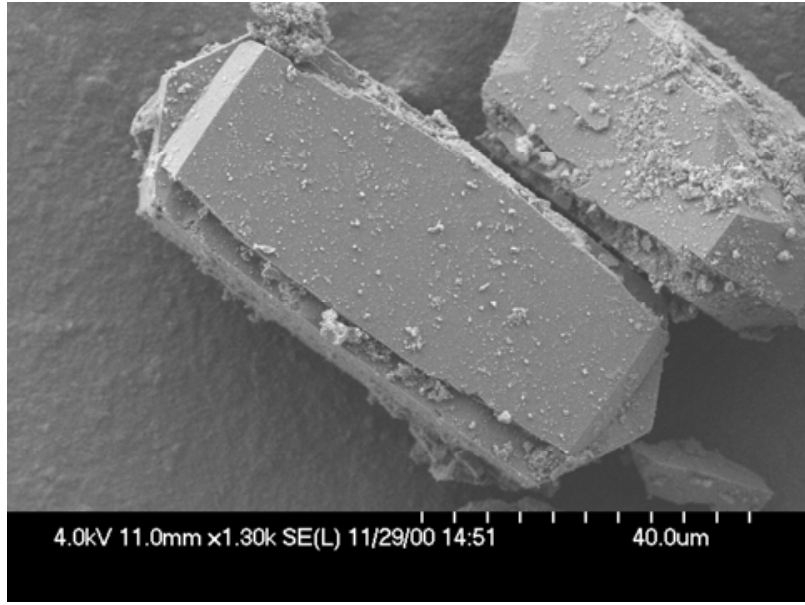

Fig. (2). SEM images of the largest crystals of ZSM-5 synthesized with $(\mathbf{a}) \mathrm{Cu}^{2+}(\mathrm{Si} / \mathrm{Al}=800),(\mathbf{b}) \mathrm{Mn}^{2+}(\mathrm{Si} / \mathrm{Al}=600),(\mathbf{c}) \mathrm{Fe}^{2+}(\mathrm{Si} / \mathrm{Al}=600)$, and (d) $\mathrm{Fe}^{3+}(\mathrm{Si} / \mathrm{Al}=600)$. 
a

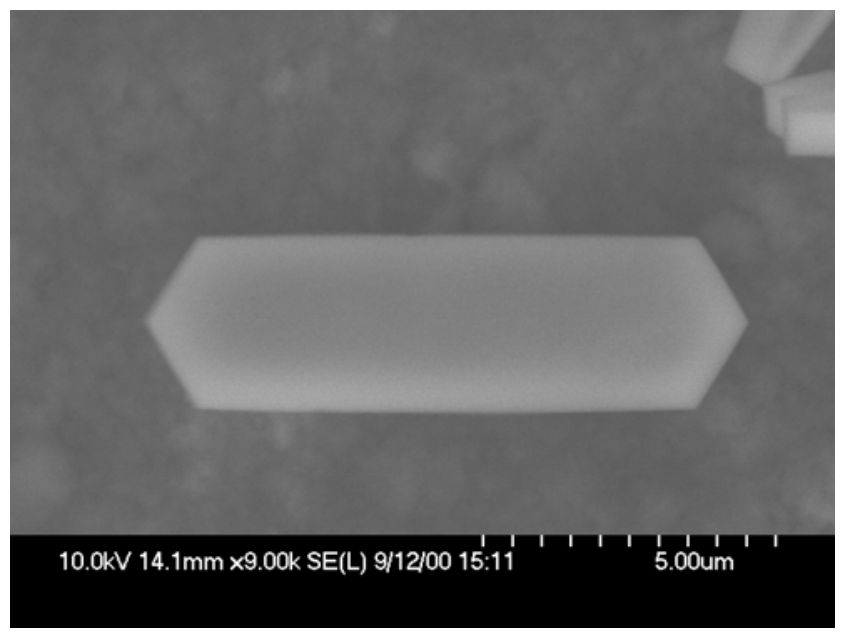

c

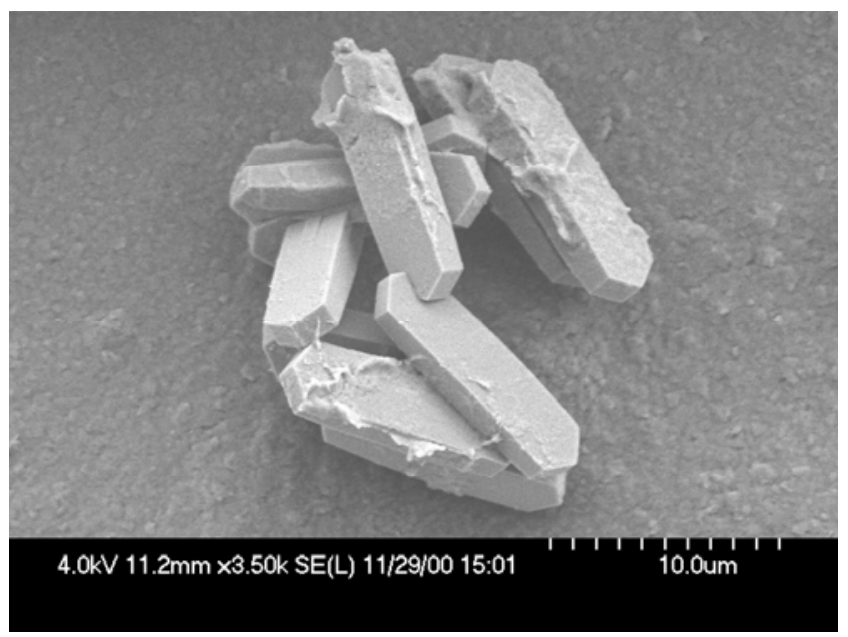

b

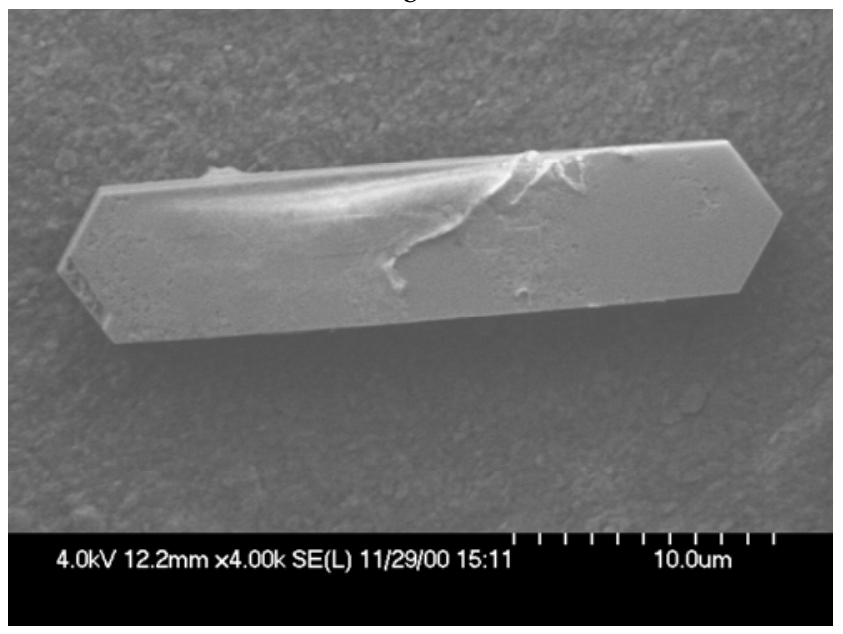

d

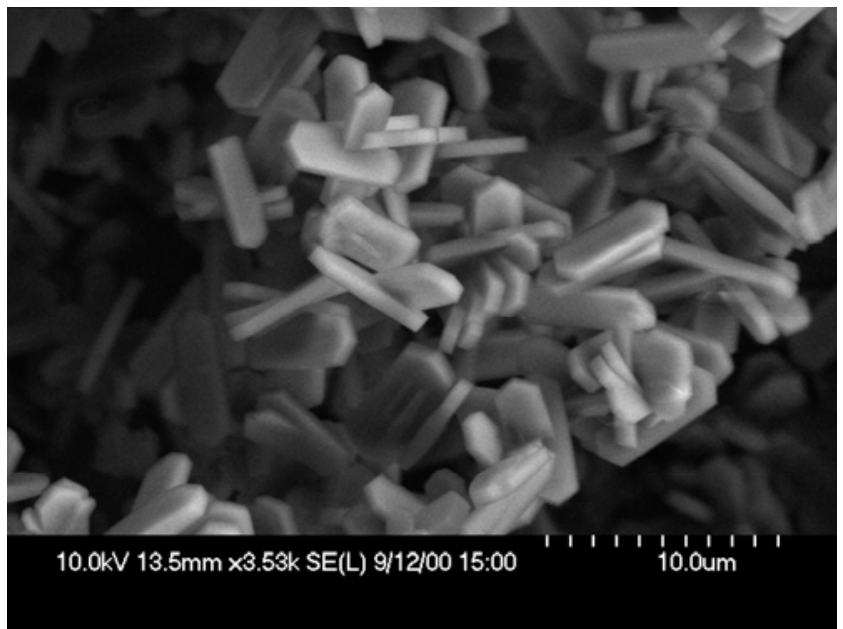

Fig. (3). SEM images of ZSM-5 synthesized according to the modified Mueller preparation [11] with (a) $\mathrm{Cu}^{2+},(\mathbf{b}) \mathrm{Mn}^{2+},(\mathbf{c}) \mathrm{Fe}^{2+},(\mathbf{d}) \mathrm{Fe}^{3+}$, and $\mathrm{Si} / \mathrm{Al}=29.5$.

Table 2. Transition Metal Analysis after Acid Washing of the Samples to Remove the Outer Layer of the Crystals. The Initial Metal Content is the Same as in Table 1

\begin{tabular}{|c|c|c|c|}
\hline Ion & $\begin{array}{c}\text { Amount of Metal in Gel (\% of T- } \\
\text { atoms) }\end{array}$ & $\begin{array}{c}\text { Amount of Metal in Sample } \\
\text { (weight\%) }\end{array}$ & $\begin{array}{c}\text { Amount of Metal in Sample (\% of } \\
\text { T-atoms) }\end{array}$ \\
\hline \hline $\mathrm{Cu}^{2+}$ & 0.1 & 0.16 & 0.166 \\
\hline $\mathrm{Mn}^{2+}$ & 0.1 & 0.13 & 0.168 \\
\hline $\mathrm{Fe}^{2+}$ & 0.1 & 0.62 & 0.747 \\
\hline $\mathrm{Fe}^{3+}$ & 0.1 & 0.076 & 0.059 \\
\hline
\end{tabular}

substitution in the outer regions of the ZSM-5 crystal. This is consistent with observations by Von Ballmoos, et al. where mapping of large crystal ZSM-5, has found that the outer zones of the crystal are more aluminum rich than the center [19]. It is also consistent with results observed for small crystal samples.

Crystals were washed in $1 \mathrm{M}$ solution of $\mathrm{HCl}$ in methanol for one hour to dissolve the outer regions and remove any amorphous material. Elemental analysis on the washed crystals

The amount of metal relative to the T-atoms is presented in Table 2.

\section{CONCLUSIONS}

ZSM-5 crystals containing $\mathrm{Cu}, \mathrm{Mn}$, and Fe were synthesized up to $85 \mu \mathrm{m}$ using a modified Charnel's method. The 
identity of the phase was confirmed by powder XRD. ICPAES was used for the elemental analysis. These crystals however were twinned, preventing single crystal XRD from being performed. Smaller untwinned crystals of $10 \mu \mathrm{m}$ have been synthesized. These are of sufficient size to use a synchrotron source to perform the single crystal XRD.

\section{ACKNOWLEDGMENTS}

The authors wish to thank Drs. Frank May and Nigam Rath of the University of Missouri-St. Louis for assistance with the powder and single crystal x-ray diffraction, and Clarissa Vierrether of the Materials Research Center at UMR for assistance with the SEM. Funding was provided by the Missouri Research Board and the University of MissouriRolla.

\section{REFERENCES}

[1] Iwamoto, M.; Yahiro, H. Catal. Today, 1994, 22, 5.

[2] Kovacheva, P.; Davidova, N.; Novakova, J. Zeolites, 1991, 11, 54.

[3] Romero, M. D.; Calles, J. A.; Rodriguez, A. Ind. Eng. Chem. Res., 1997, 36, 3533.

[4] Wellach, S.; Hartmann, M.; Ernst, S.; Weitkamp, J. Proceedings of the International Zeolite Conference, 12th, Baltimore, July 5-10, 1998, 1999, 2, 1409.
Sobalik, Z.; Dedecek, J.; Ikonnikov, I.; Wichterlova, B. Microporous Mesoporous Mater., 1998, 21, 525.

[6] Wichterlova, B.; Dedecek, J.; Sobalik, Z. Stud. Surf. Sci. Catal., 1995, 94, 641.

[7] Dedecek, J.; Wichterlova, B. J. Phys. Chem. B, 1997, 101, 10233

[8] Wichterlova, B.; Sobalik, Z.; Dedecek, J. Catal. Today, 1997, 38, 199.

[9] Itho, Y.; Nishiyama, S.; Tsuruya, S.; Masai, M. J. Phys. Chem., 1994, $98,960$.

[10] Hong, U.; Kaerger, J.; Kramer, R.; Pfeifer, H.; Seiffert, G.; Mueller, U.; Unger, K. K.; Lueck, H. B.; Ito, T. Zeolites, 1991, 11, 816.

[11] Mueller, U.; Unger, K. K. Zeolites, 1988, 8, 154.

[12] Chao, K. J.; Lin, J. C.; Wang, Y.; Lee, G. H. Zeolites, 1986, 6, 35.

[13] Yokomori, Y.; Idaka, S. Microporous Mesoporous Mater., 1999, $28,405$.

[14] Lermer, H.; Draeger, M.; Steffen, J.; Unger, K. K. Zeolites, 1985 , 5, 131 .

[15] David, T.H.; Evanina, G.; Huang, F. Polish J. Chem., 1990, 64, 295.

[16] Notari, B. Stud. Surf. Sci. Catal., 1988, 37, 413.

[17] Vu, T.A.; Falconer, J. L.; Noble, Richard D. Ind. Eng. Chem. Res., 1999, 38, 3635.

[18] Galbraith Laboratories, 2323 Sycamore Dr. Knoxville, TN 37921.

[19] Von Ballmoos, R.; Gubser, R.; Meier, W.H. Proceedings of the Sixth International Conference on Zeolites. Olson, D.; Bisio, A. Eds., Butterworth, 1984, 803.

(C) Schaeffer and Kirkby; Licensee Bentham Open.

This is an open access article licensed under the terms of the Creative Commons Attribution Non-Commercial License (http://creativecommons.org/licenses/by-nc/3.0/) which permits unrestricted, non-commercial use, distribution and reproduction in any medium, provided the work is properly cited. 